\title{
Kinetics of electroplating process of nano-sized ceramic particle/Ni composite
}

\author{
Sheng-Chang Wang, Wen-Cheng J. Wei* \\ Institute of Materials Science and Engineering, National Taiwan University, 1 Roosevelt Road, Section 4, Taipei 106, Taiwan, ROC
}

Received 10 April 2001; received in revised form 29 August 2001; accepted 31 August 2001

\begin{abstract}
Ultra-fine $\mathrm{Al}_{2} \mathrm{O}_{3}, \mathrm{ZrO}_{2}$ and $\mathrm{SiC}$ powders were co-deposited with $\mathrm{Ni}$ by electroplating from a nickel sulfamate bath. An electroplating additive $\mathrm{Na}_{3} \mathrm{Co}\left(\mathrm{NO}_{2}\right)_{6}$ can promote the co-deposition of the $\mathrm{SiC}$ particles, but the $\mathrm{Al}_{2} \mathrm{O}_{3}$ and $\mathrm{ZrO}_{2}$ particles can form composite layers without the assistance of the additive. It suggests that the complex ion $\mathrm{Co}\left(\mathrm{NO}_{2}\right)_{6}{ }^{3-}$ acts as a catalyst during the composite plating. The Guglielmi adsorption mechanism is applied to the electroplating of the ultra-fine $\mathrm{SiC}$ with Ni. The ultra-fine SiC particles are more difficult to co-deposit than the coarse $\mathrm{SiC}$, and the rate determination step is controlled by the transferal process of loose adsorption to strong adsorption. The embedded SiC concentration can be increased either by increasing electrical current density or by raising the $\mathrm{pH}$ of the suspension to 5. The existence of second ceramic phases in the co-deposited layer changes the grain shape of Ni from columnar to equiaxial, and reduces the average grain size of Ni-matrix to $50 \mathrm{~nm}$.
\end{abstract}

(C) 2002 Elsevier Science B.V. All rights reserved.

Keywords: Electroplating; Guglielmi adsorption; Nano-sized ceramic

\section{Introduction}

Composite coating has been well developed for the last two decades, dating from the first investigation in the literature by Grazen [1] in 1962. Its first application was the $\mathrm{SiC} / \mathrm{Ni}$ coating used as the wear-resistant improvement in the Wankel engine by Metzger et al. [2] in 1970, and the $\mathrm{SiC} / \mathrm{Ni}$ composite coating is still successfully used for the wear parts in the automotive industry.

The advantages of this composite coating are clear. The simultaneous deposition of the non-metal inclusions and metal phases to form composite layers brings a significant improvement on several physical and mechanical properties of the coating. The ceramic particles whose use is reported in the literature [3-9] include $\mathrm{Al}_{2} \mathrm{O}_{3}, \mathrm{SiC}, \mathrm{Cr}_{2} \mathrm{O}_{3}$, $\mathrm{TiO}_{2}, \mathrm{MoS}_{2}$, WC, etc. In addition, polymer particles such as polytetrafluoro-ethylene (PTFE) and polyethylene (PE) have also been used to reduce the friction coefficient and to achieve the anti-stick surface of the composite [10,11].

In many applications, such as hard coatings for precision molds or electroforming in the LIGA process, a co-deposition of ultra-fine particles with metal is preferable

\footnotetext{
* Corresponding author. Tel.: +886-2-2363-0231; fax: +886-2-2363-4562.

E-mail address: wjwei@ccms.ntu.edu.tw (W.-C.J. Wei).
}

to coarse particles. From our previous investigation [12], the ultra-fine $\mathrm{SiC} / \mathrm{Ni}$ composite has a smoother surface and better bonding between $\mathrm{SiC}$ and $\mathrm{Ni}$ than that of coarse $\mathrm{SiC} / \mathrm{Ni}$ composite. For $\mathrm{SiC}$ particles larger than $0.1 \mu \mathrm{m}$, there of ten is an $\mathrm{SiO}_{2}$ layer on the $\mathrm{SiC}$ particles which is weakly bonded to the Ni substrate, resulting in pores and cracks at the interface. In contrast, the interface of the ultra-fine $\mathrm{SiC}$ and $\mathrm{Ni}$ is integrated, with an interface that is free from defects. According to the Zener equation, based on the same volume particle content, the ultra-fine particles have higher numbers to inhibit the grain growth of the matrix at high temperatures.

However, there has been much research showing that the reduction of particle size will decrease the co-deposition content of the particles. Maurin and Lavanant [13] showed that the concentration of $0.1 \mu \mathrm{m}$ of $\mathrm{SiC}$ powder incorporation in rotating disc experiments in a nickel sulfate solution was less than 0.7 mass $\%$ which was closed to the detection threshold of EDX analysis. On the contrary, the concentration can reach 2 mass\% with $\mathrm{SiC}$ in size of $0.8 \mu \mathrm{m}$ and 5 mass $\%$ with $2.8 \mu \mathrm{m}$. Fransaer et al. [11] quantitatively predicted the correlation of the concentration of PE particles engulfed in copper matrix on a rotational disc electrode based on trajectory analysis. According to their model, the quantity required to co-deposit $5 \mu \mathrm{m}$ particles was calculated to be 10 times smaller than that of $20 \mu \mathrm{m}$ particles. 
Although the applications of hard metal coatings deposited by electroplating methods have been developed for a long time, the co-deposition mechanisms are still not yet well resolved. Guglielmi [3] is the first to propose a successive two-step adsorption mechanism, explaining the results related to the volume fraction of co-deposited particles $(\alpha)$ to the volume percent of particles suspended in the plating bath $(C)$ with the Langmuir adsorption isotherm. The first step in his mechanism is called loose adsorption, where particles have loose physical adsorption on the cathode with a high degree of metal ion coverage. In this step, there is a layer of adsorbed ions and solvent molecules, screening the interaction between the electrode and the particles. The second step is a strong adsorption, which is thought to be assisted by the electric field, whereby a substantially electrochemical reaction produces a strong adsorption of powders onto the electrode. The strongly adsorbed particles are then progressively engulfed by the growing metallic layer. The mathematical model can be expressed as:

$\frac{C}{\alpha}=\frac{M i_{0}}{n F \rho_{\mathrm{m}} v_{0}} \exp (A-B) \eta\left(\frac{1}{k}+C\right)$

where $M$ is the atomic weight of the electrodeposited metal, $i_{0}$ the exchanging current density, $n$ the valence of the electrodeposited metal, $F$ the Faraday constant, $\rho_{\mathrm{m}}$ the density of electrodeposited metal, $\eta$ the overpotential of electrode reaction, $i=i_{0} \exp (A \eta)$ and $k$ the Langmuir isotherm constant, mainly determined by the intensity of interaction between particles and cathode. The parameters $v_{0}$ and $B$ are related to particle deposition, and both play a symmetrical role with the parameters $i_{0}$ and $A$ related to metal deposition.

The validity of Guglielmi's model has been verified with different deposition systems, such as $\mathrm{SiC}$ and $\mathrm{TiO}_{2}$ particles with nickel from sulfamate bath [3], or $\alpha-\mathrm{Al}_{2} \mathrm{O}_{3}$ particles with copper from a copper sulfate plating bath $[14,15]$. The mechanism shows an effective and simple method to analyze the direct influence of the essential parameters in composite electroplating.

In this study, we investigate the behaviors of composite plating of ultra-fine $\mathrm{Al}_{2} \mathrm{O}_{3}, \mathrm{ZrO}_{2}$ and $\mathrm{SiC}$ powders with $\mathrm{Ni}$ to form composite coatings. The Guglielmi adsorption model was applied to analyze the kinetics occurring during deposition in order to differentiate the behaviors of coarse and ultra-fine particles. Moreover, the influence of the co-deposited $\mathrm{SiC}$ contents by the plating parameters such as solid loadings of powder, current density, $\mathrm{pH}$ and composition of the plating bath were also investigated.

\section{Experimental procedure}

Three ultra-fine ceramic powders were used in this study. One is a plasma-synthesized ultra-fine $\mathrm{SiC}$ powder (PJ-PL-SiC, PlasmaChem, GmbH, Germany), another is a nano-sized $\delta$-phase $\mathrm{Al}_{2} \mathrm{O}_{3}$ powder (PJ-PL-ALO, Wah Lee, Taiwan), and the third is an ultra-fine $\mathrm{ZrO}_{2}$ powder
(PL-D-H-ZrO, Wah Lee, Taiwan). The ultra-fine SiC showed a major phase $6 \mathrm{H}$ and the average particle size was $62 \mathrm{~nm}$. The $\mathrm{Al}_{2} \mathrm{O}_{3}$ powder has an average $30 \mathrm{~nm}$ particle size and $\delta$-phase. The average particle size and phase of the $\mathrm{ZrO}_{2}$ powder is $60 \mathrm{~nm}$ and cubic phase.

For the composite plating, unless specified in the text, a nickel sulfamate bath containing $90 \mathrm{gl}^{-1}$ nickel sulfamate (EP grade, Phibrochem, USA), $3 \mathrm{~g}^{-1}$ nickel chloride (EP grade, SHOWA, Japan), $40 \mathrm{~g}^{-1}$ boric acid (EP grade, SHOWA, Japan), and $1 \times 10^{-4} \mathrm{M}$ of sodium hexanitrocobaltate $\left(\mathrm{Na}_{3} \mathrm{Co}\left(\mathrm{NO}_{2}\right)_{6}\right.$, EP grade, Alfa Aesar, $\left.\mathrm{MA}\right)$ were added to the $\mathrm{SiC} / \mathrm{Ni}$ composite plating bath. A Cu plate as cathode with dimensions of $10 \mathrm{~mm} \times 6.5 \mathrm{~mm} \times 0.25 \mathrm{~mm}$ was used and the anode used a Ti basket containing small nickel ingots. Before plating, a sequence of cleaning and acidic etching of the $\mathrm{Cu}$ plate by diluted sulfuric acid was applied to remove contamination and grease on the surface.

The solid loading of the added powder in plating solution was up to $1.5 \mathrm{vol} . \%$ based on the bath volume. Gentle stirring of suspension by air bubbles kept the solution well dispersed. The current density was applied from 0.15 to $8 \mathrm{~A} \mathrm{dm}^{-2}$ (ASD). The bath temperature from 25 to $50^{\circ} \mathrm{C}$ was controlled within $2^{\circ} \mathrm{C}$ and the $\mathrm{pH}$ ranged from 2.0 to 6.0, as was adjusted by $\mathrm{H}_{3} \mathrm{BO}_{3}$ or $\mathrm{NaOH}$.

An electrophoretic mobility meter (Laser Zee meter 501, Pen Ken, NY) and an electrokinetics charge analyzer (ECA2000, Chemtrac Systems, GA) were used for the measurement of the $\zeta$-potential and streaming current (SC) readings, respectively. The co-deposition layer was cut and polished, and then a thin foil sample of $3 \mathrm{~mm}$ diameter prepared from the coating layer was prepared and characterized by transmission electron microscopy (TEM or HRTEM, 100CXII, FX-400E, JEOL, Japan).

\section{Results and discussion}

\subsection{Surface potential of ultra-fine particles}

The SC readings of ultra-fine $\mathrm{Al}_{2} \mathrm{O}_{3}$ and $\mathrm{ZrO}_{2}$ particles suspended in nickel sulfamate plating bath at different temperatures are shown in Fig. 1. The two powders are positively charged and their SC readings are nearly constant as the temperature of the plating solution is increased. The isoelectric point (IEP) of $\mathrm{Al}_{2} \mathrm{O}_{3}$ and $\mathrm{ZrO}_{2}$ are $\mathrm{pH} 9$ and 6 $[16,17]$, respectively. The IEP of the two powders is larger than the $\mathrm{pH}$ of the plating suspension $(\mathrm{pH}=4)$. Contrarily, The IEP of $\mathrm{SiC}$ is 3 [12]. Theoretically, the particle surface should be negatively charged in an aqueous solution of $\mathrm{pH}=$ 4. But further investigation revealed that $\mathrm{SiC}$ with negative charged surface would adsorb $\mathrm{Ni}^{2+}$ ions and change the surface polarity from negative to positive as shown in Fig. 2 . Due to the increased concentration of nickel sulfamate, the adsorbed density of $\mathrm{Ni}^{2+}$ ions on the surface of $\mathrm{SiC}$ increases. Finally, it results in the increase of $\zeta$-potential at high concentration of Ni electrolyte. 


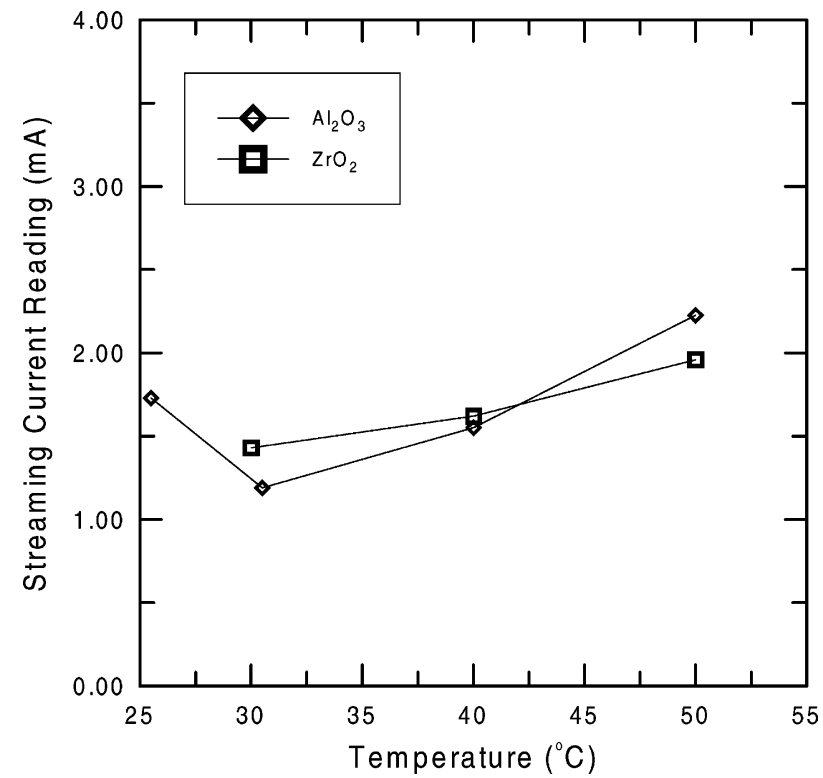

Fig. 1. SC readings of the 1 vol. $\%$ of ultra-fine $\mathrm{Al}_{2} \mathrm{O}_{3}$ and $\mathrm{ZrO}_{2}$ powders for different temperatures in the plating solution $(\mathrm{pH}=4)$.

\subsection{Influence of sodium hexanitrocobaltate}

A small addition of $\mathrm{Na}_{3} \mathrm{Co}\left(\mathrm{NO}_{2}\right)_{6}$ can promote the co-deposition of ultra-fine $\mathrm{SiC}$ particles as shown in Fig. 3. Only 0.3 vol.\% of $\mathrm{SiC}$ was co-deposition in the $\mathrm{Ni}$ matrix in the suspension without any $\mathrm{Na}_{3} \mathrm{Co}\left(\mathrm{NO}_{2}\right)_{6}$. When $2 \times 10^{-5} \mathrm{M}$ of $\mathrm{Na}_{3} \mathrm{Co}\left(\mathrm{NO}_{2}\right)_{6}$ was added to the plating bath, the embedded $\mathrm{SiC}$ concentration in Ni layer increased by about 20 times. However, further addition of $\mathrm{Na}_{3} \mathrm{Co}\left(\mathrm{NO}_{2}\right)_{6}$ did not seem to increase the $\mathrm{SiC}$ concentration. With the concentration higher than $20 \times 10^{-5} \mathrm{M}$, the coating surface lost its burnish and the layer delaminated. Fig. 4 shows the SEM micrographs of ultra-fine $\mathrm{SiC} / \mathrm{Ni}$ composites with or

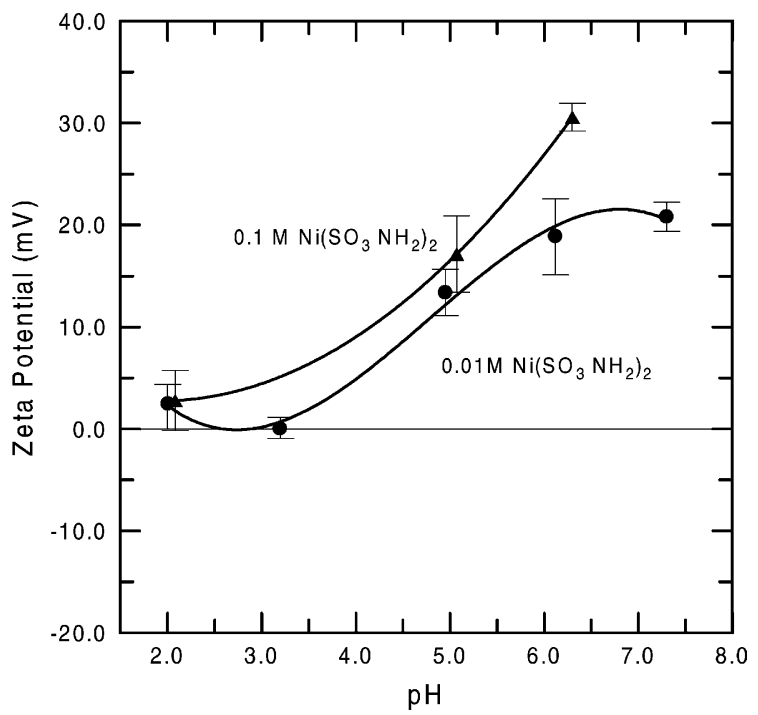

Fig. 2. $\zeta$-Potential of $\mathrm{SiC}$ with $\mathrm{pH}$ in the suspensions containing various concentrations of $\mathrm{Ni}\left(\mathrm{SO}_{3} \mathrm{NH}_{2}\right)_{2}$ as electrolyte.

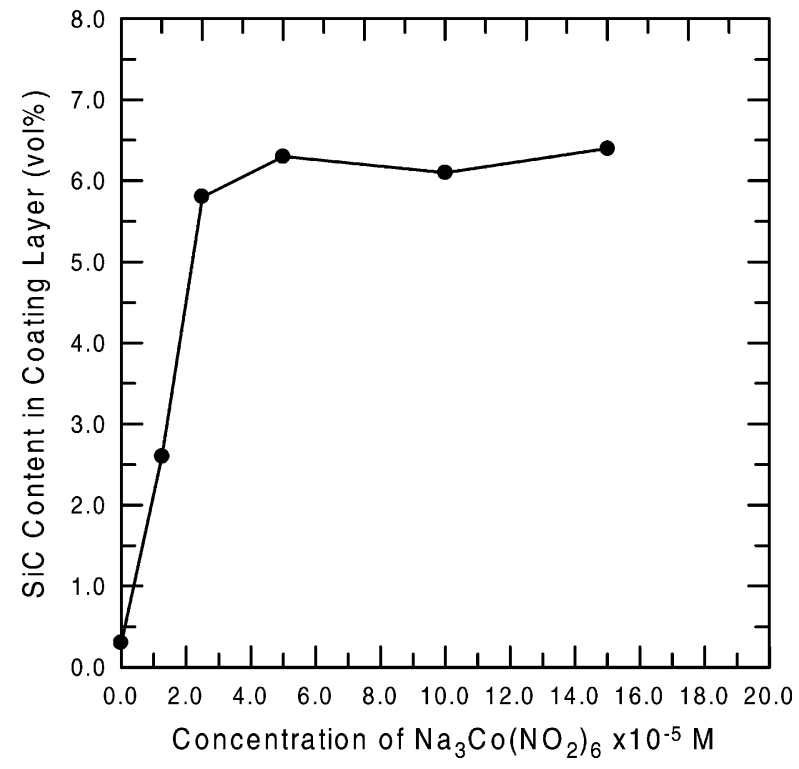

Fig. 3. Variation of $\mathrm{SiC}$ content in the $\mathrm{SiC} / \mathrm{Ni}$ composite layer by adding different concentrations of $\mathrm{Na}_{3} \mathrm{Co}\left(\mathrm{NO}_{2}\right)_{6}$.

without the addition of $\mathrm{Na}_{3} \mathrm{Co}\left(\mathrm{NO}_{2}\right)_{6}$. For the $\mathrm{SiC} / \mathrm{Ni}$ composite plating without $\mathrm{Na}_{3} \mathrm{Co}\left(\mathrm{NO}_{2}\right)_{6}$, few $\mathrm{SiC}$ particles were found in the matrix and showed cluster state. The cluster structure could be regarded as an agglomeration-like structure, and the particles inside the clusters were not in contact with each other. When $1.5 \times 10^{-5} \mathrm{M}$ of $\mathrm{Na}_{3} \mathrm{Co}\left(\mathrm{NO}_{2}\right)_{6}$ was added to the plating solution, the content of $\mathrm{SiC}$ particle in the Ni matrix increased and the distance among the $\mathrm{SiC}$ particles was uniform. As the concentration reached $15 \times 10^{-5} \mathrm{M}$, the embedded $\mathrm{SiC}$ increased further and reached a saturation level. The number of cluster structure obviously increased and the distance among the particles inside the cluster decreased.

When $\mathrm{Na}_{3} \mathrm{Co}\left(\mathrm{NO}_{2}\right)_{6}$ is dissolved in water, the cation $\mathrm{Na}^{+}$ and anion $\left[\mathrm{Co}\left(\mathrm{NO}_{2}\right)_{6}\right]^{3-}$ are readily formed in the solution. The anion $\left[\mathrm{Co}\left(\mathrm{NO}_{2}\right)_{6}\right]^{3-}$ might be adsorbed on the top of $\mathrm{Ni}^{2+}$ cation and neutralize the particle charge. Thus, the anion seems to decrease the surface potential of SiC particle and the van der Waals attractive force dominates the particle's interaction. Therefore, the distance between $\mathrm{SiC}$ particles decreases with an increase in the concentration of $\left[\mathrm{Co}\left(\mathrm{NO}_{2}\right)_{6}\right]^{3-}$.

Consequently, it is suggested that the trivalent Co complex ion acts as a catalyst during the composite plating, assisting the adsorption of $\mathrm{SiC}$ on the cathode. But a high concentration of the trivalent anion causes the $\mathrm{SiC}$ particles to form a cluster structure and to decrease the distance among the $\mathrm{SiC}$ particles in the Ni matrix.

\subsection{Adsorption kinetics of $\mathrm{SiC} / \mathrm{Ni}$}

Fig. 5 shows that the volume percentage of embedded $\mathrm{SiC}(\alpha)$ increases as the concentration $(C)$ of the $\mathrm{SiC}$ in the 

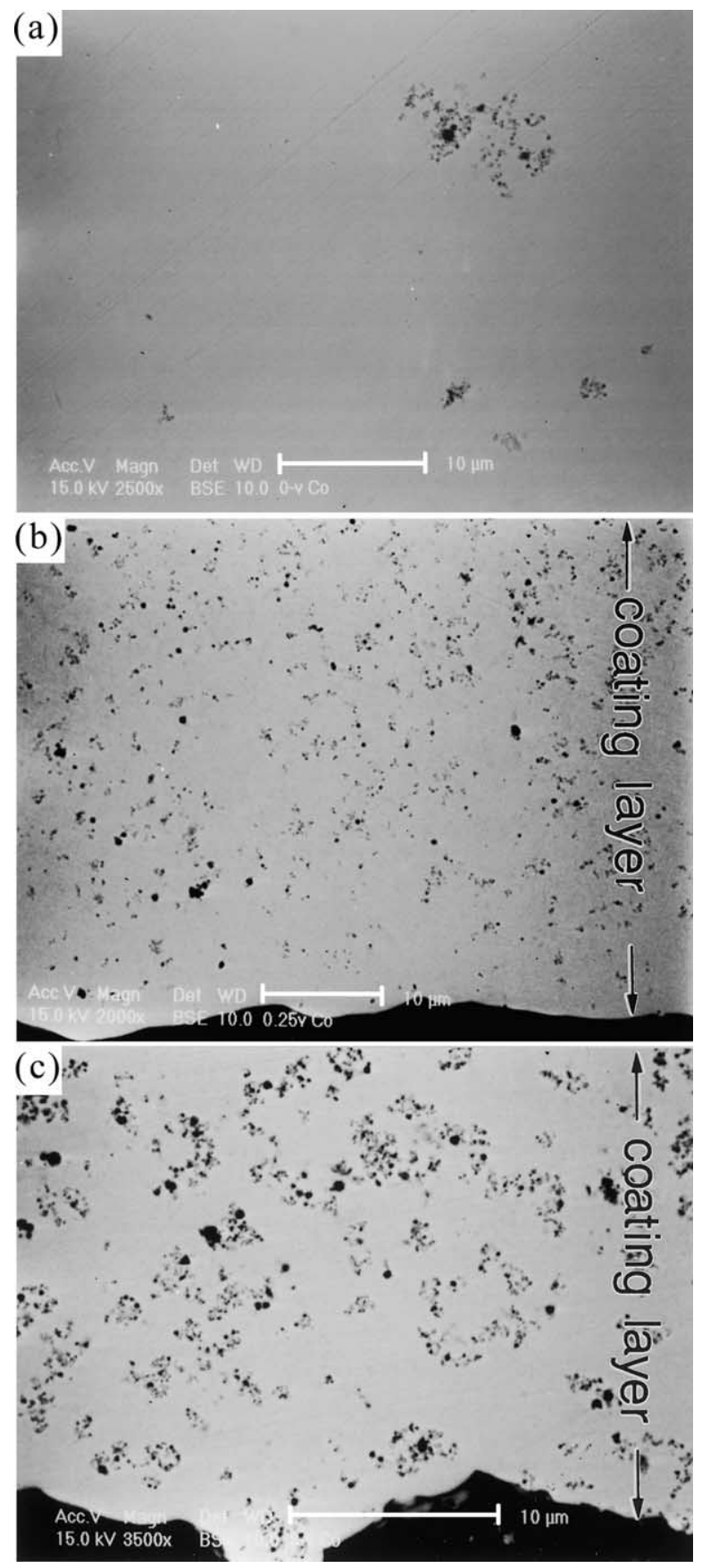

Fig. 4. SEM micrographs of ultra-fine $\mathrm{SiC} / \mathrm{Ni}$ composite plating by adding: (a) $0 \mathrm{M}$; (b) $1.5 \times 10^{-5} \mathrm{M}$; (c) $15 \times 10^{-5} \mathrm{M}$ of $\mathrm{Na}_{3} \mathrm{Co}\left(\mathrm{NO}_{2}\right)_{6}$.

suspension, referred to as an adsorption isotherm curve. According to the co-deposition model proposed by Guglielmi, Fig. 5 can be re-plotted showing $C / \alpha$ vs. $C$ at various current densities as shown in Fig. 6. Based on Eq. (1), the relationship of $C / \alpha$ and $C$ can be fitted as a straight line, which has a interception $(1 / k)$ with $C$-axis. The slope $(\tan \varphi)$ of the line is given by

$\tan \varphi=\frac{M i_{0}}{n F \rho_{\mathrm{m}} v_{0}} \exp (A-B) \eta$

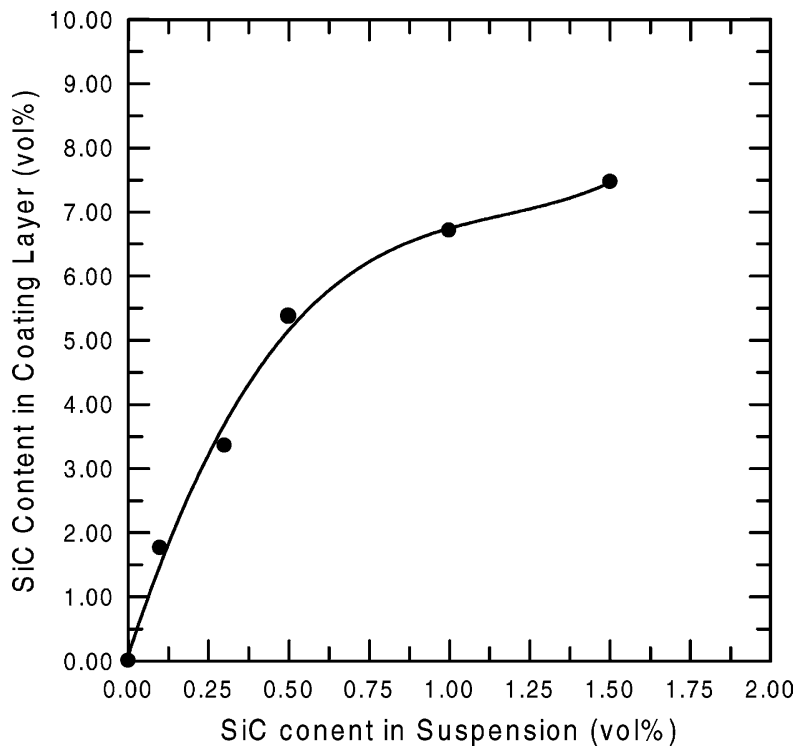

Fig. 5. Relationship of $\mathrm{SiC}$ contents in the suspension and in the composite coating. The composite plating conducted at value of $\mathrm{pH}=5$ at $50^{\circ} \mathrm{C}$.

The intercept of the line conducted for the condition $i=4$ ASD shows a value -0.46 , which gives the constant $k$ to be 2.14 for ultra-fine $\mathrm{SiC}$ particles co-deposited with $\mathrm{Ni}$ electrode. Here, $k$ indicates the net reaction constant of the particle adsorbed on the electrode surface and can be expressed as $k=k_{\mathrm{a}} / k_{\mathrm{d}}$, where $k_{\mathrm{a}}$ is the adsorption coefficient and $k_{\mathrm{d}}$ is the desorption coefficient of particles on the electrode. If $k>1$, it indicates that the adsorption rate of particles is faster than desorption rate, and vice versa. With the coarse $\mathrm{SiC}$ particles in an average size of $2 \mu \mathrm{m}$ [3], the $k$ value is 8.3 , which is larger than that of this study for ultra-fine SiC.

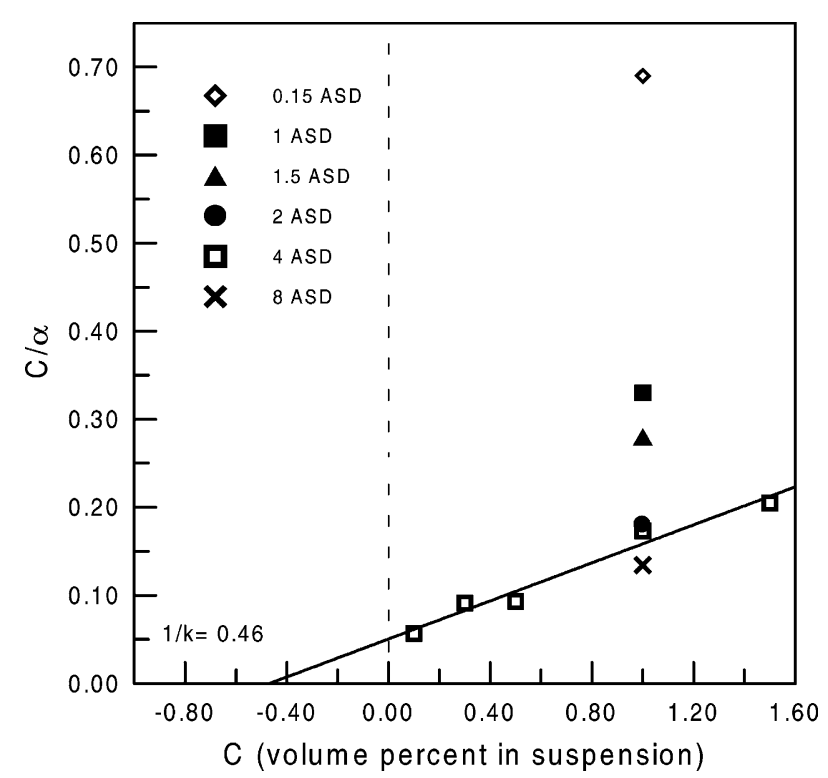

Fig. 6. Co-deposition of ultra-fine $\mathrm{SiC}$ and $\mathrm{Ni}$ according to Eq. (1) for various current densities. 
Table 1

The loose coverage and strong coverage of two-step adsorption of SiC on $\mathrm{Ni}$

\begin{tabular}{lll}
\hline$C(\%)$ & $\sigma_{1}(\%)$ & $\sigma_{\mathrm{s}}(\%)$ \\
\hline 0.1 & 17.3 & 1.76 \\
0.3 & 37.5 & 3.36 \\
0.5 & 48.9 & 5.38 \\
1 & 63.5 & 6.7 \\
1.5 & 70.6 & 7.46
\end{tabular}

This implies that the adsorption on the electrode surface of ultra-fine $\mathrm{SiC}$ particles is much more difficult than that of the coarse $\mathrm{SiC}$ particles. Once the $k$ value is obtained, the coverage of loose adsorption $\left(\sigma_{1}\right)$ particles and strong adsorption $\left(\sigma_{\mathrm{s}}\right)$ can also be computed by the Langmuir adsorption isotherm modified by Guglielmi [3] as:

$\sigma_{1}=\frac{k C}{1+k C}\left(1-\sigma_{\mathrm{s}}\right)$

where we assumed that surface coverage of strong adsorption is close to the volume fraction of the particle $(\alpha)$. Therefore, the loose adsorption coverage can be estimated by Eq. (3) and the results are shown in Table 1. The coverage of loosely adsorbed $\mathrm{SiC}$ is greater than the concentration of particles in the suspension. Furthermore, only one-tenth of the loosely adsorbed particles can be trapped into the matrix by their reduction of metal ions adsorbed on the particle surface, and consequently the particles become strongly adsorptive. As a result, the rate determined step in the co-deposition of $\mathrm{SiC}$ in the Ni sulfamate bath is controlled by the transferred process of loose adsorption to strong adsorption.

From Eqs. (1) and (2), Guglielmi deduced Eq. (4) concerning the relationship of slope $\tan \varphi$ and the current density $i$ as:

$\log \tan \varphi=\log \frac{M i_{0} B / A}{n F \rho_{\mathrm{m}} v_{0}}+\left(1-\frac{B}{A}\right) \log i$

The results of $\tan \varphi$ vs. current density between 0.15 and 8 ASD are shown in Fig. 7. The linear fitting line is plotted in the figure, and the slope of the line is -0.44 . Therefore, $B / A$ is 1.44 in Eq. (4). There are two electrodic reactions for the composite plating. One is the metal ions diffusing through the outer Helmholtz plane (OHP) [18] of electrode, being reduced and depositing on the cathode. The other is that the charged particles pass through the OHP and adsorb on the cathode. The constants $A$ and $B$ can be seen as the total charge passing through the electrode interface and carried by $\mathrm{Ni}^{2+}$ ions and charged $\mathrm{SiC}$ during the reaction. If $B>A$, it indicates that the current density increases as the concentration of $\mathrm{SiC}$ in the plating layer increases. The relation of current density and $\mathrm{SiC}$ content in the coating layer was shown in Fig. 8. The $\mathrm{SiC}$ contents increase abruptly as the current density increases to $\leq 2 \mathrm{ASD}$. When the current density increases to $>3 \mathrm{ASD}$, the increment of $\mathrm{SiC}$ content slows down to a level of 7-8 vol.\%.

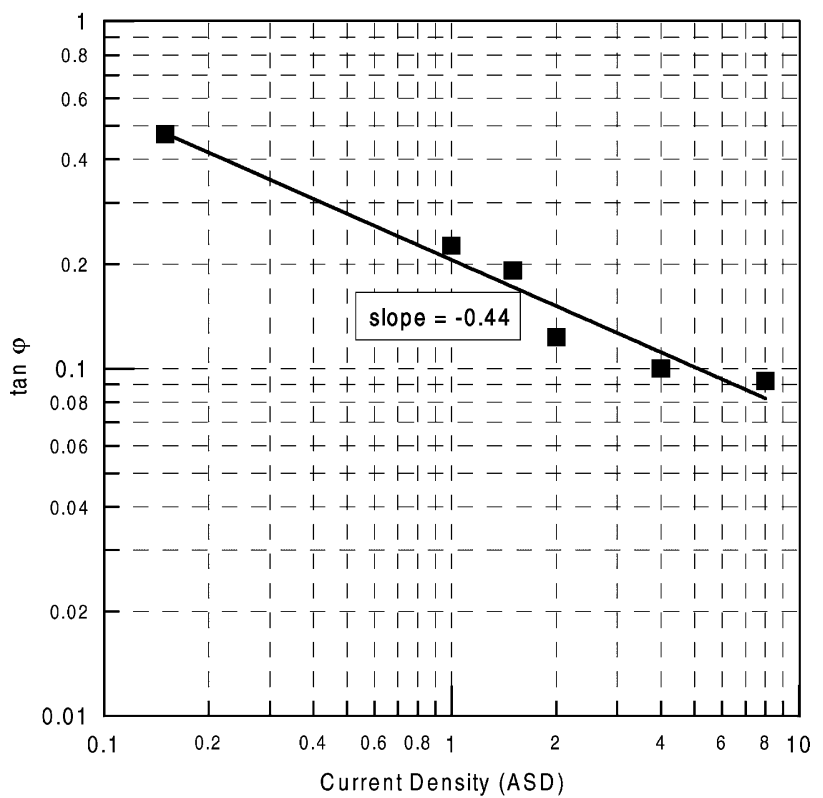

Fig. 7. Relationship of current density and the slope $(\tan \varphi)$ according to Eq. (2).

Fig. 9 shows the variation of $\mathrm{SiC}$ content with the $\mathrm{pH}$ of the plating solution. In strong acid region $(\mathrm{pH} \leq 2)$, the embedded $\mathrm{SiC}$ content is lower than 0.5 vol.\%. When the $\mathrm{pH}$ value of the suspension becomes weakly acid, the $\mathrm{SiC}$ contents increases until its $\mathrm{pH}=6$. Above $\mathrm{pH}=6$, the coating layer loses its surface brightness and cannot form a dense layer.

This phenomena can be explained by changes in the $\zeta$-potential of $\mathrm{SiC}$ in the $\mathrm{Ni}\left(\mathrm{SO}_{3} \mathrm{NH}_{2}\right)_{2}$ electrolyte as shown in Fig. 2. According to the Smoluchowski equation, a

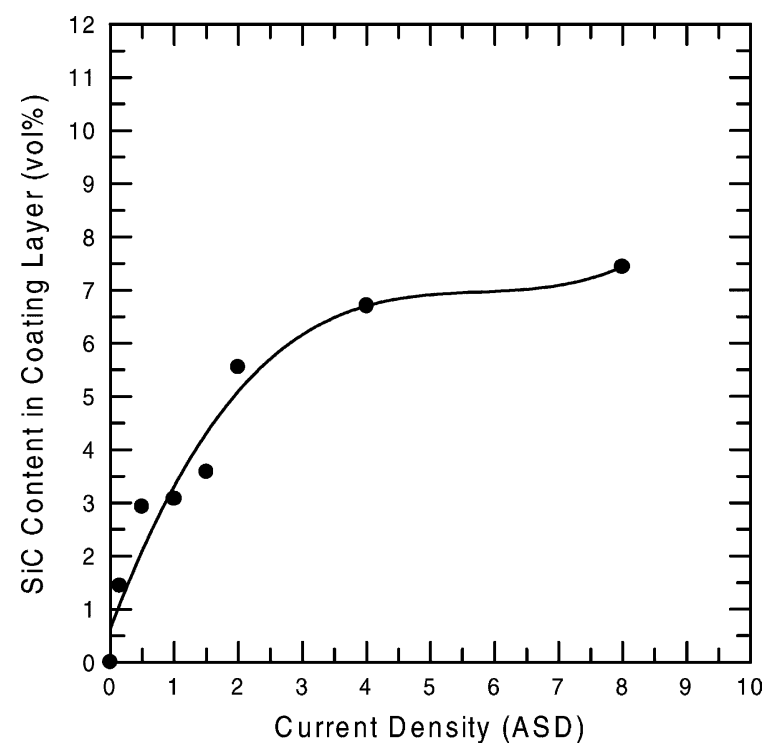

Fig. 8. Effects of current density on the concentration of $\mathrm{SiC}$ in the coating layer. 


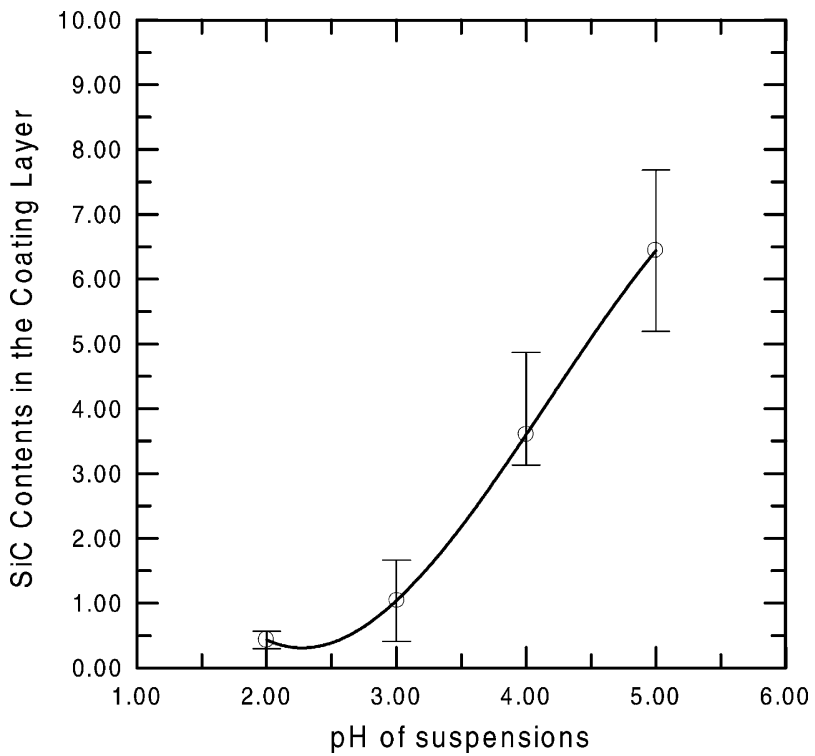

Fig. 9. Variation of $\mathrm{SiC}$ concentration in the composite layer with $\mathrm{pH}$ values of suspension.

charged particle will have a velocity $\left(v_{E}\right)$ in an electric field and can be expressed as:

$v_{E}=u_{E} E=\frac{\varepsilon \zeta}{\eta} E$

where $E$ is applied field strength, $u_{E}$ the electrophoretic mobility and $\eta$ the viscosity of the suspension. Two different processes for the co-deposition of $\mathrm{SiC}$ can be considered. One is the electrophoresis of particles near the electrode, and the other is the adsorption of the particle together with $\mathrm{Ni}$ on electrode. If the $\zeta$-potential increases, the electrophoretic mobility velocity of the $\mathrm{SiC}$ particles increases. It implies that the concentrations of the $\mathrm{SiC}$ in the suspension near the electrode are higher than that under a low $\zeta$-potential condition. The increment of the coverage of loose adsorption suggests that these particles have a higher opportunity of transferring to strong adsorption.

\subsection{Microstructure of composite layers}

Fig. 10 shows the TEM micrograph of the cross-section of the $\mathrm{Al}_{2} \mathrm{O}_{3} / \mathrm{Ni}$ composite coating, with a few clusters of $\mathrm{Al}_{2} \mathrm{O}_{3}$ particles embedded in Ni matrix. The diffraction pattern (DP) shows a ring pattern, which indicates that the $\mathrm{Ni}$ grains are polycrystalline and very small. A similar microstructure was found in $\mathrm{ZrO}_{2} / \mathrm{Ni}$ and $\mathrm{SiC} / \mathrm{Ni}$ composites, which are shown in Figs. 11 and 12, respectively. For the ultra-fine $\mathrm{ZrO}_{2}$ powders, it is difficult to disperse the particles in a highly concentrated electrolyte. Therefore, from Fig. 11(a), $\mathrm{ZrO}_{2}$ agglomeration containing particles smaller than $20 \mathrm{~nm}$ is found in the Ni matrix, and there are some pores entrapped in the agglomerate. The attached DP shows a very weak ring pattern which is indexed as cubic phase

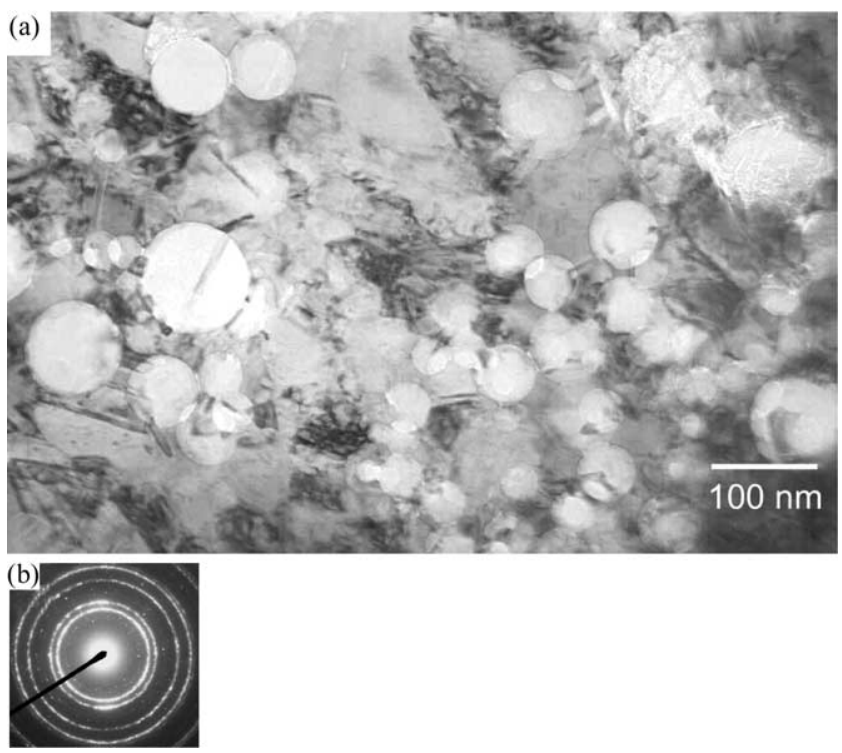

Fig. 10. TEM micrographs of (a) ultra-fine $\mathrm{Al}_{2} \mathrm{O}_{3} / \mathrm{Ni}$ composite and (b) the DP of the region.
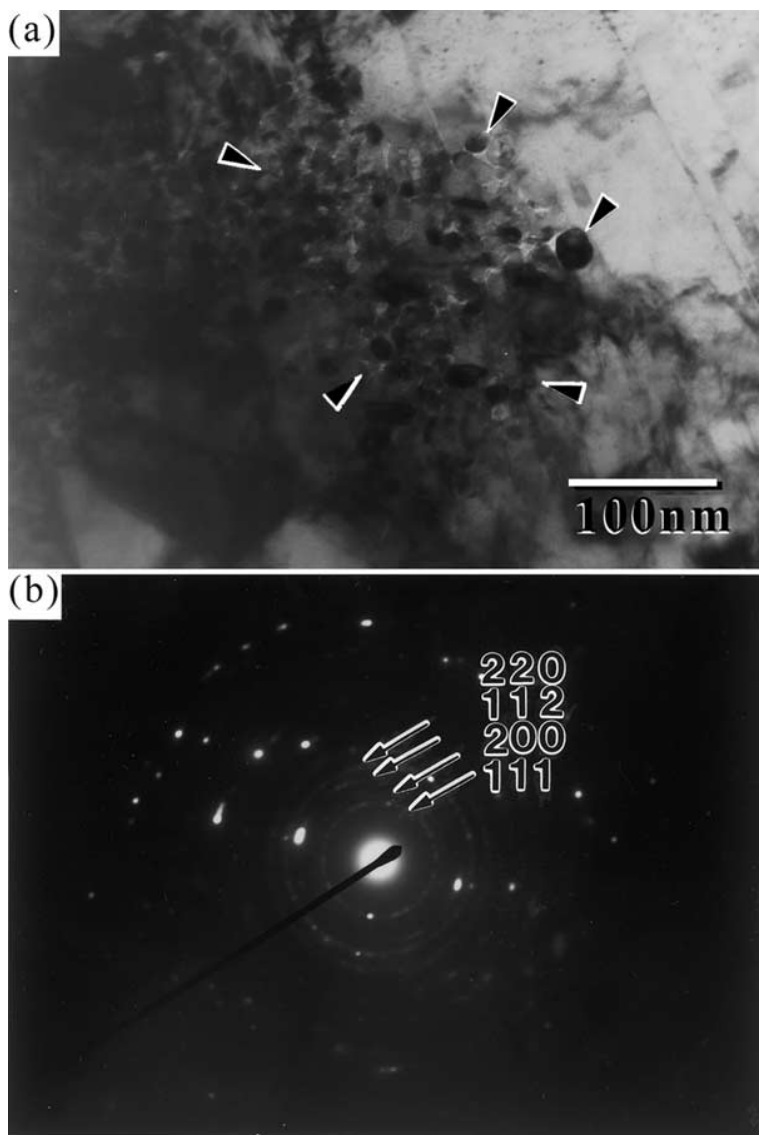

Fig. 11. TEM micrographs of the ultra-fine $\mathrm{ZrO}_{2} / \mathrm{Ni}$ composite layer: (a) BF image and (b) DP of the (a). 

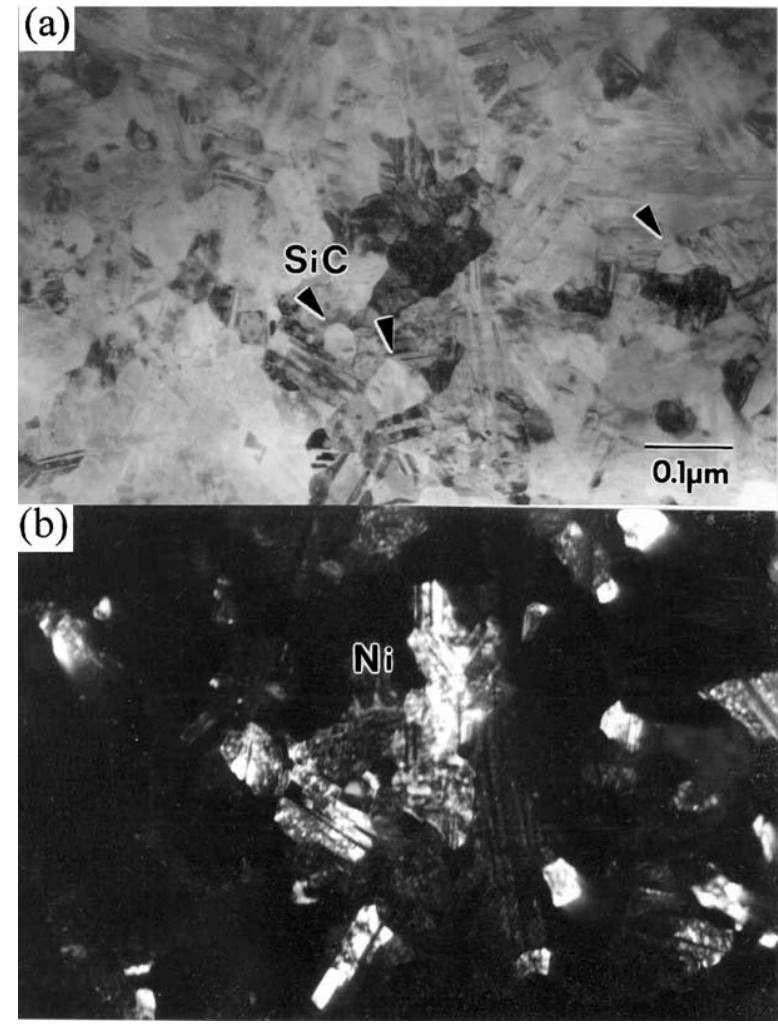

Fig. 12. TEM micrographs of ultra-fine SiC/Ni composite: (a) BF image and (b) CDF image.

$\mathrm{ZrO}_{2}$. Fig. 12(a) and (b) are the bright field (BF) and centered dark field (CDF) image, showing the $\mathrm{Ni}$ grain of $\mathrm{SiC} / \mathrm{Ni}$ composite. The average grain size of $\mathrm{Ni}$ is $50 \mathrm{~nm}$ and equiaxial in shape. The Ni grain in the pure Ni specimen shows a columnar texture with a longitudinal axis or growth direction perpendicular to the $\mathrm{Cu}$ substrate [12]. However, when the ultra-fine ceramic particles are added into the Ni matrix to form composites, the grain size and shape of the Ni are greatly reduced and modified. In addition, the shape of the $\mathrm{Ni}$ becomes equiaxial due to the presence of the second phase.

\section{Conclusion}

Nano-sized $\mathrm{Al}_{2} \mathrm{O}_{3}$ and $\mathrm{ZrO}_{2}$ particles can be co-deposited with $\mathrm{Ni}$ to form composite layers without the assistance of additive. This is because the surface charge of the powders is positive when their IEPs are larger than the $\mathrm{pH}$ of suspension. Trivalent Co complex ions, i.e. $\mathrm{Co}\left(\mathrm{NO}_{2}\right)_{6}{ }^{3-}$ can promote the co-deposition of ultra-fine $\mathrm{SiC}$ particles. It is suggested that the complex ions act as a catalyst during the composite plating. The two-step co-deposition mechanism proposed by Guglielmi is valid in the ultra-fine $\mathrm{SiC} / \mathrm{Ni}$ composite plating. The results show that the ultra-fine $\mathrm{SiC}$ is more difficult to co-deposit than the coarse $\mathrm{SiC}$, and the rate determined step is controlled by the transferring process of loose adsorption to strong adsorption. The embedded $\mathrm{SiC}$ concentration can be increased by increasing the current density or raising the $\mathrm{pH}$ of the suspension. The existence of second ceramic phases changes the Ni grains from columnar to equiaxial shape, and consequently reduces the grain size.

\section{Acknowledgements}

The authors are grateful for the funding supported by the National Science Council in Taiwan, under the contract NSC89-2216-E-002-016.

\section{References}

[1] A.E. Grazen, US Patent 3061525 (1962).

[2] W. Metzger, R. Oft, G. Laux, H. Harst, Electrodeposition of dispersed layers, Galvanoteknik 61 (1) (1970) 998.

[3] N. Guglielmi, Kinetics of the deposition inert particles from electrolytic baths, J. Electrochem. Soc. 119 (8) (1972) 1009-1012.

[4] M. Viswanathan, M. Ghouse, Occlusion plating of nickel-graphite composite, Met. Finish. 77 (10) (1979) 67-69.

[5] J. Zahavi, J. Kerbel, Properties of electrodeposited composite coating, Plat. Surf. Finish. 69 (1) (1982) 76-82.

[6] M. Ghouse, Wear characteristics of sediment co-deposited nickel-SiC composite coatings, Met. Finish. 82 (3) (1984) 33-37.

[7] N. Periene, A. Češuniene, L. Taicas, Nickel electrodeposits with improved hot oxidation and corrosion resistance by co-deposition of submicron powder, Plat. Surf. Finish. 80 (10) (1993) 73-76.

[8] K.N. Sun, X.N. Hu, J.H. Zhang, J.R. Wang, Electrodeposited Cr$\mathrm{Al}_{2} \mathrm{O}_{3}$ composite coating for wear resistance, Wear 196 (8) (1996) 295-297.

[9] V.D. Stankovic, M. Gojo, Electrodeposited composite coatings of copper with inert, semiconductive and conductive particles, Surf. Coat. Technol. 81 (1996) 225-232.

[10] M. Ruimi, R. Martinou, Galvano-Organo Traitements de Surface 595 (1989) 387

[11] J. Fransaer, J.P. Celis, J.R. Roos, Analysis of the electrolytic co-deposition of non-Brownian particles with metals, J. Electrochem. Soc. 134 (2) (1987) 1402-1408.

[12] S.-C. Wang, W.-C.J. Wei, Characterization of electro-plated composite $\mathrm{Ni}$ layers with ultra-fine $\mathrm{SiC}$ or $\mathrm{Al}_{2} \mathrm{O}_{3}$ particles, J. Mater. Res., submitted for publication.

[13] G. Maurin, A. Lavanant, Electrodeposition of nickel/silicon carbide composite coating on a rotation disc electrode, J. Appl. Electrochem. 25 (1995) 1113-1121.

[14] J.P. Celis, J.R. Roos, Kinetics of the deposition of alumina particles form copper sulfate plating baths, J. Electrochem. Soc. 124 (10) (1997) 1508-1511.

[15] C.C. Lee, C.C. Wan, A Study of the composite electrodeposition of copper with alumina powder, J. Electrochem. Soc. 135 (8) (1988) 1930-1933

[16] W.-C.J. Wei, S.J. Lu, C.L. Hsieh, Colloidal processing and fracture strength of alumina prepared form partially agglomerated theta-phase powder, J. Ceram. Soc. Jpn. 104 (4) (1996) 277-283.

[17] W.-C.J. Wei, S.-C. Wang, F.Y. Ho, Electrokinetic properties of colloidal zirconia powders in aqueous suspension, J. Am. Ceram. Soc. 82 (12) (1999) 3385-3392.

[18] R.J. Hunter, Foundations of Colloid Science, Vol. I, Oxford University Press, New York, 1986, pp. 337-341 (Chapter 6). 